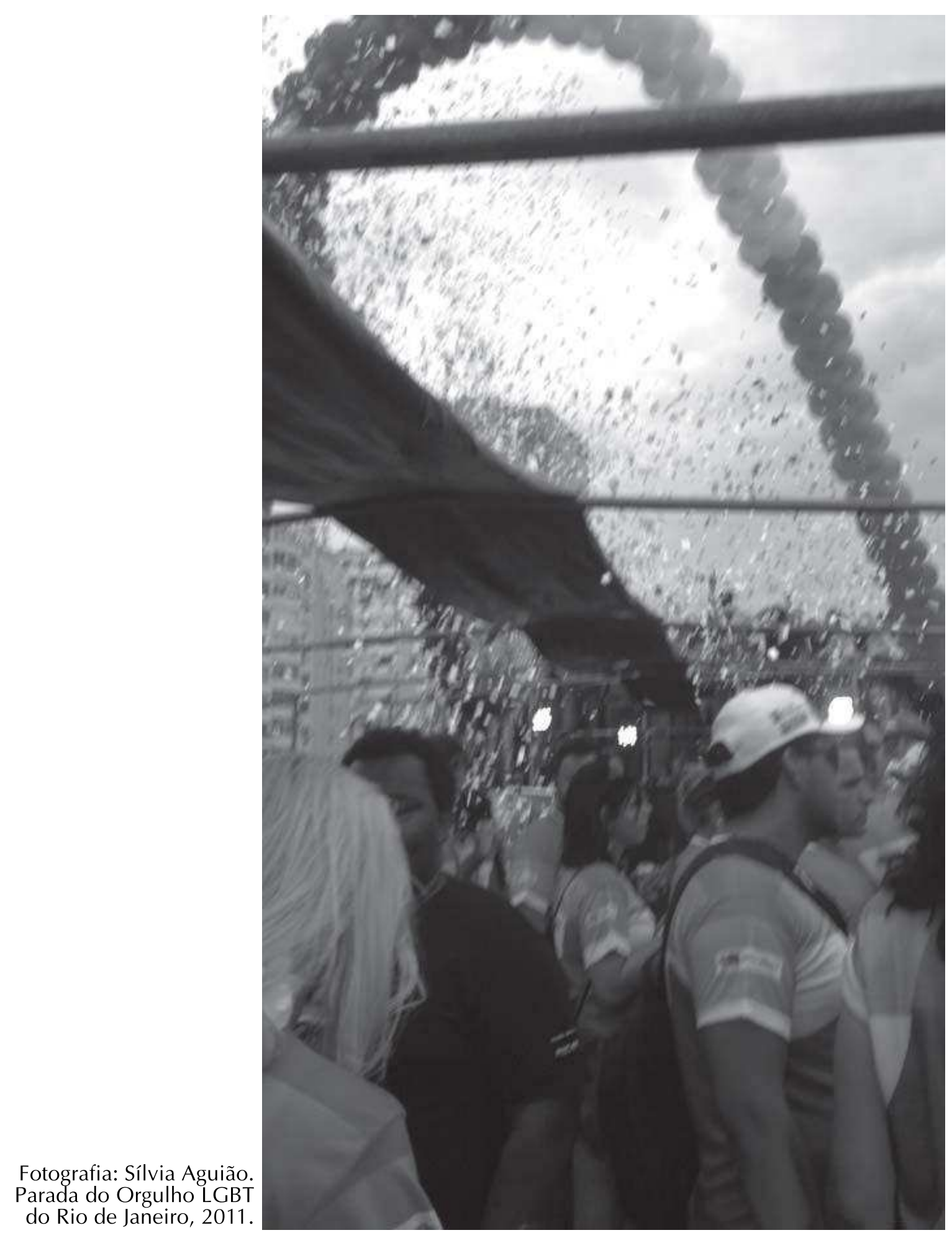




\title{
Marlise Vinagre Silva* \\ Diversidade humana, relações sociais de gênero e luta de classes: emancipação para além da cultura
}

\begin{abstract}
Resumo: Este artigo analisa de forma crítica o uso de abordagens culturalistas sobre diversidade de gênero e diversidade sexual, apontando seu limite, tendo em vista a defesa da construção de uma nova ordem social que supere o capitalismo. Defende a articulação do debate sobre a diversidade como elemento constitutivo da singularidade/originalidade dos sujeitos reais e da universalidade do gênero humano, a partir da defesa da perspectiva marxista de totalidade. Finalmente, propõe a unidade estratégica das lutas específicas em torno da diversidade de gênero e da diversidade sexual com as lutas de classe, na direção da emancipação humana.

Palavras-chave: Diversidade; gênero; luta de classes; emancipação.
\end{abstract}

\begin{abstract}
This article critically examines the use of culturist approaches on gender diversity and sexual diversity, pointing to its limit in order to defend the construction of a new social order that gets through capitalism. It advocates the articulation of the discussion on diversity as a constitutive element of uniqueness/originality of the real subjects and of universality of the human gender, from the totality perspective. Finally, it proposes a strategic unity of the specific struggles around gender diversity and sexual diversity with class struggle, in the direction of human emancipation.
\end{abstract}

Keywords: Diversity; gender; class struggle; emancipation.

\section{Introdução}

Homens e mulheres são construídos socialmente como seres resultantes do conjunto de suas relações sociais concretas objetivadas em determinada sociedade e em determinado tempo no interior da história da humanidade. Ao objetivarem-se no mundo, através do trabalho, esses homens e mulheres se autodeterminam como seres inscritos no plano da singularidade/particularidade e universalidade, por intermédio de suas relações objetivas e subjetivas com outros indivíduos sociais e com a natureza. Ao objetivarem-se como seres livres capazes de fazer escolhas, criam e recriam valores, determinada moral dominante e uma moralidade, que se objetivam no interior dessas mesmas relações sociais.

\footnotetext{
* Assistente social, doutora em Ciências Sociais pela Pontifícia Universidade Católica de São Paulo (PUC-SP) e Professora Associada da Escola de Serviço Social da Universidade Federal do Rio de Janeiro (ESS/UFRJ). E-mail: marlisevinagre@ig.com.br
} 


\section{heVigta pIII PaUtg}

\} DIVERSIDADE HUMANA, RELAÇÕES SOCIAIS DE GÊNERO E LUTA DE CLASSES - SILVA, M. V. \}

Desse ponto de vista, o valor aqui é tomado como uma categoria ontológica social, produto de relações sociais historicamente construídas. Assim, os valores e a moral, construídos social e historicamente pelos indivíduos sociais, fazem a mediação entre a universalidade da essência humana e a particularidade, com determinações impostas pelos antagonismos de classe e por densas e hierarquizadas relações de poder, nas quais se incluem as desigualdades decorrentes da condição de pertencimento de gênero, orientação e expressão sexual ou de outra natureza.

Esses antagonismos determinam condições de existência atravessadas por processos de exploração e opressão, assim como consciências alienadas, que impõem limites à efetivação da liberdade, da autonomia e da plena expansão dos indivíduos sociais, obstaculizando a realização da sua condição de ser humano genérico. Essas determinações, decorrentes das posições de classe, mas também da diversidade de gênero, da diversidade sexual e de outras, constituem solo fértil para o desenvolvimento, no interior da convivência social, de uma moral eivada de preconceito e discriminação, atendendo à necessidade de manutenção e coesão da ordem social e aos interesses das classes e dos grupos dominantes em determinada época histórica.

Como descreve Barroco (2010), a moral na sociedade capitalista:

responde à necessidade prática de estabelecimento de determinadas normas e deveres, tendo em vista a socialização e a convivência social. Faz parte do processo de socialização dos indivíduos, reproduzindo-se através do hábito e expressando valores e princípios socioculturais dominantes, numa determinada época histórica (BARROCO, 2010, p. 42).

Heller (2008), por sua vez, chama a atenção para a funcionalidade, no interior da moral da ordem vigente, dos preconceitos, entendidos como conceitos formados antecipadamente sem fundamentação científica, razoável ou plausível, ou seja, em que a base é a fé ou a irracionalidade.

A maioria dos preconceitos, embora nem todos, são produtos das classes dominantes, mesmo quando essas pretendem, na esfera do para-si, contar com uma imagem do mundo relativamente isenta de preconceitos e desenvolver as ações correspondentes. O fundamento dessa situação é evidente: as classes dominantes desejam manter a coesão de uma estrutura social que Ihes beneficia e mobilizar em seu favor inclusive os homens que representam interesses diversos (e até mesmo, em alguns casos, as classes e camadas antagônicas) (HELLER, 2008, p. 77).

Esta moral dominante, perpassada por preconceitos, gera condições para que prosperem moralismos, entendidos como julgamentos subjetivos das diferenças e dos diferentes como errado, estando baseados no preconceito, na fé/superstição ou na cegueira moral. 


\section{hevistg all pavtg}

\} DIVERSIDADE HUMANA, RELAÇÕES SOCIAIS DE GÊNERO E LUTA DE CLASSES - SILVA, M. V. \}

Assim, no interior de uma dada estrutura social, para viver e atender a suas necessidades e produzir os bens necessários para a sua existência os seres humanos transformam, por meio do trabalho coletivo, a natureza. Fazendo isso, produzemse e transformam-se a si mesmos, bem como as suas relações sociais contraditórias a partir daí produzidas.

Ao mesmo tempo em que os indivíduos se produzem e reproduzem no trabaIho, eles engendram também, a partir daí, ideias e valores que tendem a se tornar dominantes em determinada época, bem como produzem instituições sociais, produzindo a própria vida, como indivíduos humanos vivos, através de atividades práticas.

Em relação às ideias e aos valores dominantes produzidos, esses corporificam os interesses da classe e dos grupos dominantes, como demonstram Marx e Engels (2009):

As ideias da classe dominante são, em todas as épocas, as ideias dominantes, ou seja, a classe que é o poder material dominante da sociedade é, ao mesmo tempo, o seu poder estrutural dominante. (MARX E ENGELS, 2009, p. 67)

Em outras palavras, a classe dominante submete a seus interesses as ideias daqueles que subjuga em toda a extensão - os que não têm os meios para a produção material e espiritual, modelando as ideias de determinada época e apresentando-as como de todos, isto é, como universais. Mais do que isso, a classe dominante apresenta essas ideias como as únicas válidas.

A ideologia dominante no contexto da sociabilidade capitalista coloca uns indivíduos contra os outros e, nesse processo, se vale das diferentes refrações da diversidade humana e dos grandes sistemas de opressão a grupos particulares, tais como o patriarcado e a heteronormatividade. Graças à ação desses sistemas, o conjunto da moral e da ideologia dominante se mantém e tende a se reproduzir, embora com cisões internas que possibilitam a sua transformação, reafirmando-se a perspectiva que vê na liberdade do outro não a realização, mas o próprio limite à liberdade individual.

Assim, interessa apreender na totalidade da realidade social a diversidade humana, a partir dos eixos estruturadores do poder dominante na sociedade, dentre os quais os decorrentes da diversidade de gênero e sexual. Isto supõe investigar como são e como vivem os indivíduos reais, posto que, de acordo como exteriorizam sua vida, mostram suas condições materiais e espirituais de existência, incluindo aí suas representações e suas formas de consciência. Logo, deve interessar aos cientistas sociais e aos profissionais que intervêm na realidade (tais como as/os assistentes sociais, por exemplo), desvelar como os indivíduos "de carne e osso" são realmente, como agem e como atuam, condicionados pelos seus "ecos" ideológicos. Importa então desvelarmos os sujeitos no seu processo de inserção histórica real na totalidade social, sob determinadas condições concretas de experiências e vínculos sociais de pertencimento - de classe, gênero, orientação/expressão sexual, raça/etnia, geração, religião e outros. Nesse sentido, precisamos apreender os indivíduos sociais a partir 


\section{ReVistg all pgutg}

\} DIVERSIDADE HUMANA, RELAÇÕES SOCIAIS DE GÊNERO E LUTA DE CLASSES - SILVA, M. V. \}

das interconexões entre a dimensão da singularidade/particularidade e a dimensão da universalidade do gênero humano: os sujeitos realmente existentes (MARX \& ENGELS, 2009), ou seja, os homens inteiros e reais (LUKÁCS, 2007).

Tal posição nega, pois, uma noção abstrata de indivíduo, visão de inspiração metafísica ou iluminista idealista, com características de fixidez, a-historicismo, superficialidade e mesmidade, e reafirma o valor da totalidade, nos termos da concepção marxista de totalidade aberta, densa de múltiplas determinações, na qual é consubstancial a diversidade da riqueza do humano genérico.

A noção de totalidade aberta em Marx, contrapondo-se à concepção de totalidade em Hegel da "mítica ideia absoluta", refere-se ao fluxo da história real da humanidade. Nesta concepção, os indivíduos sociais, homens e mulheres, em quaisquer níveis em que os consideremos, devem ser tomados a partir do conjunto das relações ativas que são por eles mantidas com outros sujeitos e com a natureza (KONDER, 2009, p. 126).

É nesse sentido, que o presente artigo pretende problematizar a temática da diversidade humana como estratégica para o propósito da luta de classe com a finalidade de construção das condições objetivas - materiais e espirituais - para a gestação de uma nova ordem societal, libertária e emancipada.

\section{Alienação, consciência e emancipação}

No cotidiano, valores e normas são construídos e reproduzidos socialmente, embora o indivíduo os introjete/sinta/viva e os defenda com convicção como próprios e não como exigência externa. Assim, o indivíduo reproduz esses valores, contribuindo para a sua naturalização e para a primeira forma de consciência - a consciência alienada: "essa forma será a base, o terreno fértil, onde será plantada a ideologia como forma de dominação" (IASI, 2007, p. 20).

Ao viver de forma alienada, o ser humano se coisifica, se torna mercadoria e o fruto de seu trabalho se torna estranho a ele próprio. Nesse processo, se distancia de si mesmo e da natureza, se vende para o outro para sobreviver individualmente, deixando o trabalho de ser um meio de conexão entre o ser humano e a humanidade. Assim, a alienação do ser humano se coloca em relação à natureza, a si mesmo e à sua espécie, sendo formada uma visão do ser humano sobre si, sobre o seu trabalho e sobre o mundo, de modo acrítico, fragmentado e distorcido, além de naturalizado.

Porém, como a ideologia é um conjunto contraditório de ideias sobre o real, por mais eficiente que esta seja, o próprio desenvolvimento das forças produtivas contribui para que exista uma discrepância entre as relações interiorizadas como arranjo ideológico relativamente estável e a forma real como as relações operam na realidade concreta e dinâmica. Com isso, uma crise ideológica se instala, o que é vivido conflituosamente pelo indivíduo. Isso pode gerar sentimentos e comportamentos vividos no plano da subjetividade, em que podem prosperar tanto conformismos, reafirmando-se a consciência alienada, como formas de resistências, possibilitando a elevação da consciência, metamorfoseando-a em consciência em si.

Quando um indivíduo observa contradições entre valores antes assumidos e novas relações vividas por outros ele pode começar a superar o estágio alienado de consciência e se colocar em um patamar qualitativamente mais elevado. Trata-se 


\section{hevistg em pautg}

\} DIVERSIDADE HUMANA, RELAÇÕES SOCIAIS DE GÊNERO E LUTA DE CLASSES - SILVA, M. V. \}

nesse caso de assumir a "consciência em si" (IASI, 2007, p.28), quando o indivíduo passa a reivindicar direitos, seja através de participação em lutas populares ou sindicais, seja através dos movimentos culturais feministas, sexuais (homossexuais, travestis/transexuais, entre outros) e raciais (negros/as, indígenas, entre outros grupos).

$\mathrm{Na}$ consciência em si, o indivíduo vive as contradições, identificando-se com determinada identidade cultural - com uma identidade de gênero ou com determinada identidade sexual - em que a diferença vivida na qualidade de categoria social é o fulcro para o desenvolvimento do processo identificatório, bem como para a aglutinação de reivindicações e lutas por melhores condições de existência.

Essas lutas ultrapassam a dimensão do eu singular, portanto do indivíduo egoísta, situando-se ao nível de demandas coletivas pelo conhecimento da diversidade. Contudo, as demandas quase sempre ainda aparecem como lutas particulares ou "específicas", em torno de opressões vividas no contexto da cotidianidade e de vivências no interior de relações imediatas.

Corroborando com lasi (2007), entendemos que essa consciência, embora importante no contexto da luta contra opressões particulares, tais como por condição de gênero e/ou de orientação/expressão sexual, e na defesa de direitos humanos, apresenta certo limite de análise e, por conseguinte, um limite na práxis política, sobretudo em termos dos instrumentos utilizados - passeatas, negociações no parlamento (como audiências públicas e outras). Os limites situam-se em termos da ocorrência de lutas de natureza específica e às vezes até fragmentária, com pouca ou quase nenhuma consciência de classe e sem articulação com lutas de caráter radicalmente emancipatório. Ao contrário, aqui a diversidade aparece exaltada e entendida nos termos de um "conjunto de diferenças que se expressam nos contornos de cada manifestação no mundo plural" (RANGEL, 2011, p. 16).

Mas há que se considerar em relação a este aspecto que, no seio de uma sociabilidade que dissemina o individualismo egoísta, é extremamente difícil a elevação de consciência de classe - e, assim, a união e organização com base na classe -, dos segmentos subalternizados por processos de exploração e dominação.

Portanto, como advertem Marx e Engels (2009), a condição para a superação das opressões - de classe e de cultura - e da condição alienada está associada, de um lado, ao desenvolvimento das forças produtivas (até que a alienação se torne insuportável), e de outro, à existência de "indivíduos histórico-universais", organizados em escala mundial.

\section{Diversidade de gênero e sexual como expressões da diversidade humana: pensando para além da cultura}

As lutas particulares nucleadas a partir das chamadas políticas de identidade, tais como as políticas de gênero ou aquelas dirigidas a grupos sexuais, como lésbicas, gays, bissexuais e transgêneros (grupos denominados como "população LGBT"), têm se caracterizado, em sua maioria, como políticas fragmentárias, transitórias e, muitas vezes, despolitizadas em relação à defesa de mudanças estruturais na sociedade. Assim, não raramente, carecem de "qualidade de consciência de classe" nas reivindicações, embora possam, potencialmente, contribuir para a construção da emancipação política e do projeto político de transformação societária. 


\section{heVigta pIII PaUtg}

\} DIVERSIDADE HUMANA, RELAÇÕES SOCIAIS DE GÊNERO E LUTA DE CLASSES - SILVA, M. V. \}

O risco que aí se coloca situa-se no fato de que estas ações fragmentadas podem contribuir indiretamente para a legitimação da ordem burguesa, caso estas políticas não se articulem a uma perspectiva histórico-crítica e de totalidade. Essa articulação implica no reconhecimento do movimento das contradições e dos antagonismos de classes, na apreensão da totalidade, da dialética dos contrários e do movimento de negação no interior da vida social.

Do ângulo da análise e da luta em torno do reconhecimento da liberdade como valor ético central e das diferenças decorrentes da diversidade de gênero e sexual, sua vinculação à perspectiva classista permitiria o ataque simultâneo de todas as opressões, o que aponta para a radicalização da tomada de consciência da totalidade do processo de alienação e a articulação de todos os sujeitos sociais que resistem e lutam contra os processos de dominação-exploração, negando-se e ultrapassando-se abordagens fragmentárias:

Trata-se de reconhecer o valor da liberdade e das diferenças apreendendo-se o processo construído socialmente de conversão das diferenças em hierarquizações, desigualdades e discriminações alicerçadas em preconceitos, através da ação de ideologias classistas, sexistas, racistas e homofóbicas. Mas é fundamental assinalar que a defesa do valor das diferenças e dos grupos socialmente discriminados não deve cair em posturas reforçadoras de idealismos metafísicos, de essencialismos e da fragmentação (VINAGRE, 2009, p.109).

Isso requer o aprimoramento da articulação dos diversos grupos que compõem a classe trabalhadora. Só assim se poderiam fortalecer os laços de solidariedade entre esses sujeitos coletivos que, na luta concreta, podem (e devem) ter sua consciência de classe elevada e fortalecida. Nesse caso, todos esses sujeitos poderiam passar a se perceber como sujeitos revolucionários que lutam contra a mesma ordem dominante: a ordem burguesa. Isso possibilitaria fazer avançar o projeto emancipatório em direção à emancipação humana, possibilitadora da igualdade substantiva, do respeito à natureza e à vida em todas as suas formas, bem como do convívio solidário entre os sujeitos sociais em suas diferenças. Assim, as diferenças então poderiam ser tomadas como inerentes à própria riqueza do gênero humano (BOGO, 2010).

Defendemos neste trabalho o ponto de vista de que o contexto atual do capitalismo traz alguns efeitos no que diz respeito à questão da diversidade. Em primeiro lugar, a ordem burguesa nega e inviabiliza a possibilidade de satisfação de necessidades criadas socialmente em torno da diversidade; necessidades estas criadas no interior desta mesma ordem, o que em si mesmo já deixa a nu a contradição inerente ao próprio modo de produção ancorado na acumulação e na propriedade privada, na posse, no individualismo egoísta e na competitividade.

Em segundo lugar, a ordem burguesa apropria-se da exaltação da diferença e do verdadeiro modismo em torno da apologia do multiculturalismo, em relevo a partir dos anos 1970 (CUCHE, 1999) e explorado pela retórica pós-moderna. Neste caso há o risco de esta sociabilidade vir a estimular, a partir do referente diferença, 


\section{hevistg all pavtg}

\} DIVERSIDADE HUMANA, RELAÇÕES SOCIAIS DE GÊNERO E LUTA DE CLASSES - SILVA, M. V. \}

a produção/reprodução social de identidades culturais fragmentadas, classificando indivíduos que, ao mesmo tempo em que são rejeitados e discriminados são também incluídos, muitas vezes através das chamadas políticas de ação afirmativa. Essas políticas, não tendo como objetivo a superação da ordem burguesa, são evidentemente importantes armas para minorar graves situações de negação de direitos. No entanto, no caso do campo da diversidade de gênero e sexual, são muitas vezes desenvolvidas, em parte como resultado do relativo poder de pressão de grupos raciais, feministas e de grupos LGBTs e em parte pela prevalência da lógica mercadológica que inclui esses segmentos na condição de consumidores, transformando suas necessidades e desejos em objetos de posse, o que alimenta a reprodução da coisificação das relações sociais na sociedade vigente. O problema que se verifica aqui é analisado por Barroco no excerto abaixo reproduzido:

a coisificação das relações humanas transforma escolhas, capacidades, sentimentos, afetos e valores em objetos de desejo e de posse. Mais do que isso, inverte-se o valor da existência humana e das coisas ao fetichizar os objetos, dotando-os de humanidade e transferindo suas 'virtudes' aos compradores (BARROCO, 2008, p. 158).

Como problematiza Santos (2010 a), "o projeto societário vigente, quando assimila estas reivindicações, coloca, sob seu controle, as respostas que, em geral, tendem à burocratização, à fragmentação e à mercantilização" (SANTOS, 2010 a, p. 191). Em outras palavras, ao ocorrer a assimilação das demandas particularizadas nas esferas de gênero e diversidade sexual, se efetiva o processo de coisificação das relações e, assim, a ampliação da dominação e da alienação.

Cabe aqui fazer referência à forma legitimadora da dominação - identidade alienada - a que Bogo (2010) faz referência, quando a diversidade, como a de gênero e a sexual, é tratada de forma cindida em relação à totalidade da vida social e distanciada da finalidade da conquista da emancipação humana, ainda que esse fim seja incorporado nos discursos dos sujeitos que desenvolvem atividades teóricas de ensino e pesquisa e/ou que atuam no "campo da diversidade".

Ocorre que sem intencionalidade consciente quanto ao resultado da ação, o resultado da atividade humana se distancia das finalidades propostas nas práticas discursivas. Esta inadequação é resultado da própria forma de estar no mundo, uma vez que "os fins são produtos da consciência" (VAZQUEZ, 2007, p. 222).

Do nosso ponto de vista, essa abordagem refere-se muitas vezes a ações com intenções meramente denunciatórias. Esta abordagem da diversidade, tratada em si mesma, só é superada mediante ações práticas de caráter um pouco mais politizado (mesmo que ainda particulares e desarticuladas da dimensão de classe), incluindo estratégias de visibilidade, sobrevivência do grupo e resistência à opressão, ou mediante outra modalidade de ação em torno da diversidade, agora com mais consciência e envolvendo um projeto cultural de tornar positivas as representações e posições sociais ocupadas pelos grupos em questão. Aqui, entendemos que está em jogo o recurso à estratégia de luta pela consolidação e ampliação de direitos ainda na ordem burguesa, tendo como horizonte a emancipação política. 


\section{ReVistg all pgutg}

\} DIVERSIDADE HUMANA, RELAÇÕES SOCIAIS DE GÊNERO E LUTA DE CLASSES - SILVA, M. V. \}

Corroborando a opinião de Bogo, o projeto, mais do que cultural, deve ser de transformação estrutural. Logo, parafraseando o autor, o projeto de luta de feministas e de militantes LGBT, se quiser ter uma perspectiva radicalmente emancipatória - de luta revolucionária -, isto é, com um projeto político voltado para a "identidade emancipada" (BOGO, 2010: 59-60), deve visar à totalidade da vida social e não apenas às particularidades de gênero e de orientação e expressão sexual.

Este formato de tratamento do tema da diversidade somente se objetiva a partir da vivência organicamente articulada entre as esferas da atividade teórica, da vivência da cultura popular e revolucionária, como ato prático e não contemplativo, e a esfera da práxis política emancipatória propriamente dita (BOGO, op. cit., p.125). Essa orgânica articulação seria com certeza extremamente estratégica para a construção das condições objetivas para a unidade da luta por uma sociedade emancipada.

Contudo, para essa articulação se concretizar, não basta a elevação de consciência dos grupos nucleados em torno das opressões de gênero e das decorrentes da diversidade sexual. Faz-se necessário igualmente o amadurecimento teórico, ético e político, com busca de novas estratégias e táticas, das lutas dos sujeitos políticos com potencial classista revolucionário, incluindo-se aqui os movimentos democráticos e populares, os sindicatos combativos e, especialmente, os partidos revolucionários.

Para que possa avançar a unidade revolucionária é fundamental que sejam construídas alianças em bases legítimas e tecidos laços de uma real solidariedade de classe, o que não é uma tarefa nada fácil, ainda que condições objetivas dadas pela crise do capital sejam favorecedoras.

Para tanto, a classe deve atentar para a heterogeneidade de sua composição interna, atravessada por mediações de gênero, diversidade sexual e outras, assumindo na análise e na atividade prática que ela é constituída pelos sujeitos vivos e realmente existentes, conforme mencionado anteriormente.

Assim, a concepção de identidade que serve ao fortalecimento do projeto ético e político emancipatório deve visar à ultrapassagem da perspectiva culturalista de política de gênero e de política LGBT strictu sensu, de desenho particularista e fragmentário, possibilitando o adensamento do projeto de emancipação humana para além dos direitos, no plano da busca pela emancipação política no interior da institucionalidade do Estado burguês.

Vale lembrarmos, então, nas palavras de Frederico (2009) a concepção de Marx acerca dos limites da emancipação política:

A emancipação humana, reclamada por Marx, é aquela que permite a absorção do cidadão abstrato pelo homem individual, que faz deste, em sua vida cotidiana, um ser genérico solidário com os seus semelhantes. Isso não se consegue com a emancipação política, que mantém o homem preso à condição de indivíduo egoísta da sociedade civil, e sim com a supressão do Estado enquanto momento de expressão da alienação do homem (FREDERICO, 2009, p. 99). 


\section{hevistg all pavtg}

\} DIVERSIDADE HUMANA, RELAÇÕES SOCIAIS DE GÊNERO E LUTA DE CLASSES - SILVA, M. V. \}

Assim, o horizonte teleológico das políticas de identidade deve ser o da "eticidade radical" (BARROCO, 2010) que necessariamente precisaria contemplar a transformação das relações no mundo do trabalho e da cultura - incluindo-se aí os valores, a moral, a ética, a moralidade, o imaginário, as representações, as práticas sociais, os modos de vida, costumes, hábitos, comportamentos, sentimentos, a afetividade e os desejos.

Caracteriza-se aqui, nesta abordagem, a concepção de cultura como mediação estratégica para alteração das condições objetivas e subjetivas de existir e viver, através da práxis revolucionária, pois sem alterar as ideias e a cultura dominantes não se operarão mudanças qualitativas nas relações materiais da sociedade. Ou seja, se queremos construir a possibilidade real de construção de uma nova estrutura social, portadora de outra sociabilidade, temos como tarefa a superação do poder espiritual hegemônico.

Queremos chamar a atenção aqui neste ponto para o fato de que os modos de pensar, sentir e agir, que constituem as formas de ser características das identidades culturais, precisam também ser compreendidos como constitutivos do conjunto das ideias dominantes e não como ideias verdadeiras e puramente oriundas e próprias dos diferentes grupos sociais - mulheres, LGBT e outros - e da classe que "vive do trabalho" (ANTUNES, 2003). Essas formas de ser são sentidas, vividas e reproduzidas como verdades no cotidiano, dando materialidade à "falsa consciência" e à alienação, através de processos de naturalização, conforme buscamos problematizar anteriormente.

Para fazer ultrapassar a ordem dominante e seus processos de dominação/ exploração, essas formas de ser, ancoradas em desvalores (HELLER, 2008) próprios da sociabilidade do capital, devem ser desveladas e desnaturalizadas, assim como práticas de resistência, expressas pela subversão do instituído, devem ser gestadas e encetadas.

Para efetivação do projeto de emancipação humana é necessário, então, a luta concomitante (envolvendo as dimensões econômica, política, cultural e ideológica) contra todas as formas de exploração e opressão, o que inclui contrapor-se a todas as formas de preconceito, discriminação, arbítrio e violência (simbólica e física). Supõe, também, a defesa e a luta pela radicalização, como norte de todos os direitos humanos, civis, políticos, sociais, econômicos, ambientais e culturais: "dessa forma, a revolução cultural não está separada da revolução social" (BOGO, 2010, p.168).

Ao contrário, a revolução cultural como um todo, qualificada por uma formação intelectual crítica, envolve a própria transformação dos sujeitos sociais concretos e sua organização e expressa um importante campo no interior do conteúdo da luta revolucionária, uma vez que explicita o conteúdo das táticas e estratégias, bem como explicita contra quais inimigos lutar para subverter o poder dominante. Os inimigos a que se está aqui fazendo referência são todos os setores que constituem a sustentação sócio/ideo/cultural dos poderosos: o sexismo, o racismo, a heteronormatividade e a xenofobia.

Para tanto, é preciso construir uma nova cultura que, tendo como fundamento a liberdade e a autonomia, assuma referências morais de uma nova ética - radical 


\section{ReVistg all pgutg}

\} DIVERSIDADE HUMANA, RELAÇÕES SOCIAIS DE GÊNERO E LUTA DE CLASSES - SILVA, M. V. \}

democrática e emancipatória -, o que requer o respeito à diversidade, tomada na sua dimensão ontológica e articulada à leitura de totalidade do gênero humano.

O problema da esquerda no Brasil é que ela não se propõe a ultrapassar o limite da luta pela defesa dos direitos humanos $(\mathrm{DH})$ e da conquista dos "direitos da cidadania", que acaba se constituindo na sua própria teleologia, o que resulta em ações programáticas reformistas, como analisa Santos (2010 b), ao dizer que:

(...) se fortaleceu o ideário de defesa da cidadania, dos direitos humanos e da democracia como horizonte máximo de um projeto de esquerda. (...) A emancipação política tornou-se meta e o horizonte da esquerda, no lugar da transformação radical da sociabilidade do capital (...) é fundamental o conhecimento pelas forças do trabalho do fim que se quer atingir: o aperfeiçoamento desta ordem ou sua superação. (...) As lutas pela realização dos $\mathrm{DH}$ consistem numa necessidade histórica diante do avanço do conservadorismo moral (...) diante da reprodução de formas de opressão que obstaculizam o reconhecimento da diversidade humana em todas as suas expressões. As lutas pela realização dos DH têm valor estratégico se contribuem para explicitar a desigualdade social, as formas de exploração e de opressão vivenciadas. O enfrentamento e a superação desses problemas exigem mais do que realização dos $\mathrm{DH}$, exige uma nova forma de organizar as relações sociais, fundada no trabalho associado e na socialização da riqueza material e espiritual produzida (SANTOS, 2010 b, p. 32- 35).

Isso implica desvelar a opacidade do real e superar sua aparência fenomênica, desvendando hierarquias mistificadoras e falseadoras da realidade, desnaturalizando o senso comum que nos impõe um status quo, como a única verdade, dada, fixa e imutável. Contrapor-se à cultura dominante requer também a ousadia de resgatar formas autônomas e alternativas de pensar, sentir e fazer próprias da cultura popular, ancoradas em valores sociocêntricos, tais como experiências de movimentos progressistas do campo e de algumas comunidades tradicionais remanescentes de quilombos e indígenas, que resistem e lutam pela propriedade coletiva da terra e pela preservação de sua história, língua, crenças e costumes, como patrimônio imaterial.

O desenvolvimento da tarefa de construção de uma moral de conteúdo revolucionário só é possível com o investimento na formação e na organização, que se alimentam mutuamente, envolvendo todos os sujeitos políticos e todas as frentes de batalha em uma construção histórica de uma cumplicidade revolucionária baseada na interdependência, indivisibilidade, complementaridade e universalidade, em prol da construção da emancipação humana da sociedade.

Neste projeto libertário está implícita a ideia de solidariedade ampliada, expressa na sua práxis em um companheirismo verdadeiro, vivo e substantivo, sensível à imperiosidade da defesa da liberdade para toda a humanidade. 


\section{hevistg em pautg}

\} DIVERSIDADE HUMANA, RELAÇÕES SOCIAIS DE GÊNERO E LUTA DE CLASSES - SILVA, M. V. \}

\section{Considerações finais}

Em decorrência da característica de imersão do indivíduo vulgar na cotidianidade, espaço de (re)produção do eu/singular, do pragmatismo, da repetição acrítica de valores negativos (de "desvalores", recorrendo novamente a Heller) e de preconceitos, a consciência cristaliza-se nessa etapa das lutas particulares e não chega a articular a análise das contradições existentes no atual estágio de desenvolvimento da sociedade capitalista a partir da articulação singularidade/particularidade/universidade e da visão de totalidade.

$\mathrm{Na}$ verdade, a própria sociabilidade capitalista impõe a todos os seres humanos processos de alienação e reificação obstaculizantes da análise crítica baseada na contradição e na totalidade, prevalecendo a análise parcial e fenomênica da realidade, assim como as respostas às necessidades mais imediatas e pontuais.

Entretanto, os oprimidos - quem tem fome, quem não tem emprego ou salário digno, quem não tem terra e teto, quem sofre violência e discriminação por gênero, condição de orientação sexual, raça, etnicidade, religião, situação física, mental, quem não tem acesso ao ensino superior - têm pressa e precisam realmente aqui e agora de respostas concretas na demanda por necessidades reais.

Assim, as lutas particulares são necessárias e constituem mesmo uma mediação política estratégica entre a consciência individual alienada, produto da sociabilidade liberal/burguesa, as práticas de resistência voltadas à conquista e ampliação dos chamados direitos humanos, no plano da emancipação política, è consciência revolucionária, que pode levar à superação da sociedade burguesa e à emancipação humana.

Vale lembrar certamente o que destaca Marx (2005) quanto à ilusão jurídica da possibilidade da efetivação plena dos direitos no interior da ordem burguesa, na qual o limite é a conquista de direitos do homem burguês no plano da igualdade formal abstrata e não da igualdade real e substantiva, assim como o que adverte lasi (2007) quando diz: "somos, no máximo, indivíduos da sociedade burguesa, dispostos a destruí-la". Assim, temos que admitir os limites reais existentes para a elevação da consciência a patamares superiores no interior desta ordem vigente.

Contudo, o reconhecimento da diversidade humana e das necessidades de lutas específicas daí decorrentes, associadas às diversas lutas populares e à luta de classes em prol da construção de uma nova ordem, é certamente condição para a gestação das bases objetivas e subjetivas para a transição de um modo de produção para outro, em que germine e floresça uma nova sociabilidade, possibilitadora da emancipação humana.

Para além da mera identificação com outros indivíduos por partilhar características, interesses, necessidades e demandas comuns, o indivíduo deve buscar simultaneamente se reconhecer no outro em sua genericidade como ser humano. Isto é, devemos procurar nos reconhecer na humanidade que nos caracteriza, na qual a diversidade é simultaneamente aquilo que nos singulariza e o que nos iguala como humanos, se acreditamos que como humanos "somos todos diferentes". Nesse sentido, a diferença é igual a todos os humanos.

O desafio está na aventura de nos lançar na travessia da igualdade abstrata (que vige e que constrói todas as subjetividades) para a igualdade substantiva, germe da emancipação humana. 


\section{ReVistg all pgutg}

\} DIVERSIDADE HUMANA, RELAÇÕES SOCIAIS DE GÊNERO E LUTA DE CLASSES - SILVA, M. V. \}

Se concordarmos com a tradição teórica marxiana que vincula a emancipação humana à superação da mercadoria, da propriedade privada e do Estado, a tarefa mais ambiciosa colocada situa-se em lutar radicalmente pela liberdade, o que inclui contrapor-se a todas as formas de dominação e exploração, mas essencialmente em superar todas as relações que produzem a alienação. Isso só será efetivado quando todos os seres humanos assumirem com autonomia e consciência o controle da história, o que implica reafirmar a dimensão teleológica do sujeito, que se objetiva sob condições concretas no dia a dia da práxis humana.

Isto é, as forças populares organizativas, nucleadas em torno de necessidades (mais do que legítimas) no plano da particularidade, têm potencial revolucionário. Entretanto, para participarem efetivamente da superação desta ordem societária, rumo à emancipação humana, essas forças carecem de uma articulação consciente e de uma integração com as lutas macrossociais, ligadas à efetivação do projeto socialista. 


\section{hevistg all pavtg}

\} DIVERSIDADE HUMANA, RELAÇÕES SOCIAIS DE GÊNERO E LUTA DE CLASSES - SILVA, M. V. \}

\section{Referências bibliográficas}

ANTUNES, R. Adeus ao trabalho? Ensaio sobre as metamorfoses e a centralidade do mundo do trabalho. 9 ed. São Paulo: Cortez, 2003.

BARROCO, M. L. S. Ética e Serviço Social: fundamentos ontológicos. São Paulo, Cortez, 8ª edição, 2010.

BOGO, A. Identidade para além da cultura. In: Identidade e Luta de Classes. 2 ed. São Paulo: Expressão Popular, 2010.

CUCHE, D. Cultura e Identidade. In: A Noção de Cultura nas Ciências Sociais. Bauru: EDUSC, 1999.

FREDERICO, C. O jovem Marx: 1843-1844 as origens da ontologia do ser social. 2 ed. São Paulo: Expressão Popular, 2009.

HELLER, A. O Cotidiano e a História. 8 ed. São Paulo: Paz e Terra, 2008.

IASI, M. Ensaios sobre Consciência e Emancipação. São Paulo: Expressão Popular, 2007.

KONDER, L. Marxismo e alienação: contribuição para um estudo do conceito marxista de alienação. 2a Edição. São Paulo: Expressão Popular, 2009.

LUKÁCS, G. O Jovem Marx e outros escritos de filosofia. In: Pensamento Crítico, n. 9. Rio de Janeiro: Editora UFRJ, 2007.

MARX, K. A Questão Judaica. São Paulo: Centauro, 2005.

MARX, K. \& ENGELS, F. A Ideologia Alemã. São Paulo: Expressão Popular, 2009.

RANGEL, M (org.). Diversidade, diferença e multiculturalismo: valores essenciais da pluralidade social. Niterói: Intertexto, 2011.

SANTOS, S. M. M. Política Social e Diversidade Humana: crítica à noção de igualdade de oportunidade. In: BOSCHETTI, I.; BEHRING, E. R.; SANTOS, S. M. de M. dos; MIOTO, R. C. T. (Org.). Capitalismo em Crise: Política Social e Direitos. São Paulo: Cortez Editora, 2010, v. 1, p. 185-194.

SANTOS, S. M de M. dos. Direitos Humanos, dominação ideológica e resistência. In: Revista Inscrita, n. 12, CFESS, Brasília, 2010 b.

VÁZQUEZ, A. S. Filosofia da práxis. São Paulo: Expressão Popular, 2007.

VINAGRE, M. Ética, Direitos Humanos e Projeto Profissional Emancipatório. In: FORTI, V. e GUERRA, Y. (orgs). Ética e Direitos: Ensaios Críticos. Rio de Janeiro: Lumen Juris, 2009. - (Coletânea Nova de Serviço Social).

Recebido em 23 de setembro de 2011

Aceito para publicação em 15 de dezembro de 2011 